\title{
When push comes to shove
}

We congratulate Dr Gandet and colleagues ${ }^{1}$ for a successful exclusion of a rapidly enlarging chronic type A aortic dissection involving the ascending and arch in a patient with an extremely "hostile" chest.

"Hostile" is an oftentimes overused term in surgery to imply inaccessible access. However, in this case, it is truly appropriate. The authors ${ }^{1}$ devised a technically demanding and very complicated approach to exclude this aneurysm that was truly "hybrid." By using a reversed debranching approach, the great vessels were debranched with the origin of blood flow arising from the left subclavian artery. The left subclavian artery ostium was maintained via an onthe-table fenestrated thoracic endovascular aortic repair (TEVAR) graft. This required a transapical approach with cardiopulmonary support. The authors successfully excluded the aneurysm but, ultimately, the patient died as a result of stroke and pulmonary complications.

Gandet and colleagues ${ }^{1}$ are to be commended for devising and executing a complex approach for a patient who truly had no other option. Many of the techniques established in transcatheter aortic valve replacement are applicable to TEVAR when treating the ascending aorta, such as a transapical approach and rapid ventricular pacing during deployment of device. The transapical approach provides a more precise deployment and has less anatomic restrictions compared with the transfemoral approach, ${ }^{1}$ while rapid ventricular pacing allows for immediate reduction of systemic pressure and minimizes migration of the device. $^{2}$

Although the use of cardiopulmonary bypass for control of hemodynamics may be redundant during transapical TEVAR if the aneurysm is limited to the ascending aorta, in this case the complex nature of multiple zones 0,1 , and 2 deployment necessitated the hemodynamic support provided during deployment of the multiple devices. As complex a procedure as this one was, the question is not whether we can do the procedure, it's should we?

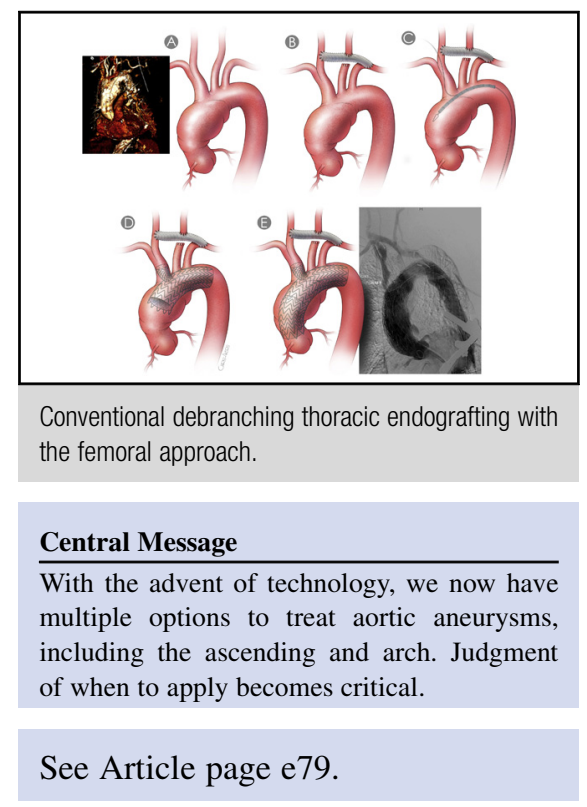

As the number of complex aortic cases continues to grow worldwide, ${ }^{3,4}$ we will face an increasing number of patients who are older, have more comorbidities, are more frail, and have had prior cardiac procedures. During the past decade, hybrid and totally endovascular approaches have allowed us to expand our armamentarium for the treatment of this complex patient population.

But how far should we push the envelope? There are certain patients who will not benefit from an intervention-regardless of how minimally invasive. These are the patients in whom we should not operate. They remain difficult to identify, and further work is required to provide better prediction models for intervention. As our surgical community becomes subject to public scrutiny, however, a climate of risk aversion begins to pervade. Thus, one can appreciate the difficulties in practicing our trade in the current era, which requires a balance between deciding how and when to intervene (and how invasive to intervene) juxtaposed upon maintaining the respect and dignity of each patient.

There is no question that Gandet and colleagues ${ }^{1}$ pushed the envelope. In fact, some may contend that they shoved it. But as long as the dignity of the patient was maintained, the authors provided new knowledge - that this approach could be technically achieved. More important, the authors ignored risk aversion and, ultimately, provided the patient and family with something more valuable-hope. So, when push comes to shove, shove. 


\section{References}

1. Gandet T, Alric P, Bommart S, Canaud L. Endovascular aortic repair of a chronic ascending and arch aortic aneurysm. J Thorac Cardiovasc Surg. 2018;155:e79-83.

2. Walther T, Dewey T, Borger MA, Kempfert J, Linke A, Becht R, et al. Transapical aortic valve implantation: step by step. Ann Thorac Surg. 2009;87:276-83.
3. Lichtenstein SV, Cheung A, Ye J, Thompson CR, Carere RG, Pasupati S, et al. Transapical transcatheter aortic valve implantation in humans: initial clinical experience. Circulation. 2006;114:591-6.

4. Grover A, Gorman K, Dall TM, Jonas R, Lytle B, Shemin R, et al. Shortage of cardiothoracic surgeons is likely by 2020. Circulation. 2009;120:488-94. 